\title{
O papel do tribunal de contas da união no controle dos serviços públicos delegados
}

\author{
Marcio André Santos de Albuquerque ${ }^{1}$
}

\section{Resumo}

O objetivo deste artigo é demonstrar a forma de atuação do Tribunal de Contas da União (TCU) no controle dos serviços públicos delegados. Para tanto, foi realizada ampla pesquisa doutrinária acerca do termo serviço público, concluindo-se não existir unanimidade entre os juristas acerca do assunto. No início do século XX, a prestação dos serviços públicos era quase totalmente suportada pelo Estado. Aos poucos, os particulares começaram a assumir essa atividade, por meio de delegação daquele a estes. Entre outros fatores que acarretam essa transferência, pode-se citar a necessidade de diminuir o tamanho do Estado, a fim de minorar os custos da máquina administrativa. Para não haver prejuízo à sociedade com a prestação de serviços públicos de baixa qualidade, fez-se necessária a criação de organismos capazes de regular a relação entre os cidadãos e os agentes delegados. No ordenamento jurídico brasileiro, tal mister está a cargo das agências reguladoras, que realizam o controle primário sobre a forma como os serviços estão sendo prestados, verificando, entre outros aspectos, se o interesse público está sendo atendido, bem como se as tarifas cobradas condizem com o pactuado por ocasião da delegação outorgada pelo Estado. O TCU realiza o controle secundário por meio do qual verifica se as agências reguladoras estão cumprindo seus deveres legais e constitucionais. Ao final, será possível concluir que o papel do TCU é fundamental para garantir a prestação de serviços eficientes aos cidadãos. Cumpre esclarecer que o presente artigo não foi publicado em qualquer outro veículo.

Palavras-chave: Controle. Serviço Público. Delegação. Agências Reguladoras. Tribunal de Contas da União.

${ }^{1}$ Graduado em Ciências Aeronáuticas pela Academia da Força Aérea, Bacharel em Direito e Mestrando em Direito e Políticas Públicas. 


\section{Introdução}

O objetivo deste trabalho é demonstrar como o Tribunal de Contas da União (TCU) atua no controle dos serviços públicos delegados.

Para melhor compreensão do tema, de início, serão gastas poucas linhas para apresentação do Tribunal de Contas da União, com definição de suas principais competências, bem como de sua composição. Neste tópico será visto de onde advém a competência da Corte de Contas para fazer o referido controle.

Em seguida, serão apresentados os pensamentos de importantes doutrinadores acerca do tema serviço público. Será visto que a prestação de serviços ao público ocorre desde a mais primitiva forma de Estado, mas que o modo de sua prestação variou bastante de acordo com o tempo e o local. Em razão desse fato, a definição do termo serviço público vem se mostrando um grande desafio para os estudiosos do assunto.

O final da Guerra Fria juntamente com a crise financeira ocorrida em diversos países na segunda metade do século XX pode ser considerado um divisor de águas na forma como os serviços públicos são prestados. Nesse sentido, será visto que muitos países vão delegar aos particulares a prestação desses serviços.

A última parte deste trabalho vai enfocar o controle exercido pelo Tribunal de Contas da União nos serviços públicos concedidos e permitidos, fazendo-se distinção entre o papel da Corte de Contas e o das agências reguladoras. Na oportunidade, será explicitado se o TCU pode realizar ou não controle diretamente sobre os concessionários e permissionários. Convém, desde logo, deixar claro que o Tribunal de Contas, para a consecução dessa tarefa, vai utilizar importante ferramenta: a auditoria operacional.

Vale destacar ainda que, a título de ilustração, serão apresentadas algumas decisões do TCU capazes de demonstrar a importância desse tipo de controle. 


\section{Composição e competências do Tribunal de Contas da União}

O artigo 73 da Constituição Federal estabelece que o Tribunal de Contas da União é composto por nove ministros, sendo todos nomeados pelo Presidente da República. O parágrafo primeiro do referido dispositivo prevê que, para o cargo, podem ser nomeados brasileiros que tenham mais de 35 e menos de 65 anos; idoneidade moral e reputação ilibada; notórios conhecimentos jurídicos, contábeis, econômicos e financeiros ou de administração pública; e mais de dez anos de exercício de função ou de efetiva atividade profissional que exija os conhecimentos ora mencionados.

A forma de escolha dos ministros é estabelecida no parágrafo segundo do artigo 73. Dos nove ministros, três (um terço) são escolhidos pelo Presidente da República, com aprovação do Senado Federal, sendo dois alternadamente dentre auditores e membros do Ministério Público junto ao Tribunal, indicados em lista tríplice pelo Tribunal, segundo os critérios de antiguidade e merecimento. Os outros seis (dois terços) são escolhidos pelo Congresso Nacional.

Os ministros do Tribunal possuem como principal função relatar os processos que serão apreciados pelos colegiados da Corte de Contas: Plenário, Primeira e Segunda Câmaras. Convém ressaltar que, além dos nove ministros, existem no TCU quatro auditores que também relatam processos, esses são chamados ministros-substitutos.

De início, é necessário dedicar algumas linhas para explicar a relação entre o Tribunal de Contas da União e o Congresso Nacional. Em três passagens, a Constituição Federal deixa assente que o titular do controle externo em nosso ordenamento jurídico é o Poder Legislativo: artigos 31, caput, 70, caput, e 71, caput. Em outras duas, coloca os tribunais de contas como órgãos que devem prestar auxílio na realização do controle externo: artigo $31, \S 1^{\circ}$ e o próprio caput do art. 71 .

Apesar de auxiliar o Congresso Nacional, a Constituição Federal concedeu competências próprias e privativas ao Tribunal de Contas da União, razão pela 
qual, segundo a doutrina do Professor Hely Lopes Meirelles, a Corte de Contas pode ser considerada órgão independente. ${ }^{2}$

Com efeito, as diversas competências previstas nos incisos do artigo 71 da Constituição Federal pertencem ao Tribunal de Contas da União e não ao Congresso Nacional. Vale acrescentar que existem outras competências atribuídas ao Tribunal espalhadas no corpo da Carta, tal qual a prevista no artigo 161, parágrafo único, que confere ao TCU o dever de efetuar os cálculos das cotas referentes aos fundos de participação dos Estados e Municípios.

Para o objetivo deste trabalho, interessa, particularmente, o artigo 71, incisos IV e IX, da Constituição Federal, os quais apresentam a seguinte redação:

Art. 71. [...]

IV - realizar, por iniciativa própria, da Câmara dos Deputados, do Senado Federal, de Comissão técnica ou de inquérito, inspeções e auditorias de natureza contábil, financeira, orçamentária, operacional e patrimonial, nas unidades administrativas dos Poderes Legislativo, Executivo e Judiciário, e demais entidades referidas no inciso II; [...]

IX - assinar prazo para que o órgão ou entidade adote as providências necessárias ao exato cumprimento da lei, se verificada ilegalidade;

Dos referidos dispositivos, pode-se depreender que o constituinte originário concedeu ao Tribunal de Contas da União competência para fazer inspeções e auditorias nas unidades administrativas nos Poderes Legislativo, Executivo e Judiciário, bem como em outras entidades que gerenciem, arrecadem, guardem, administrem ou utilizem recursos públicos federais.

Dessa forma, compete ao Tribunal de Contas da União verificar se os administradores pautam as suas gestões em ações que se realizam em consonância

2 Órgãos independentes, nas palavras do ilustre professor, são os originários da Constituição e representativos dos Poderes de Estado - Legislativo, Executivo e Judiciário - colocados no ápice da pirâmide governamental, sem qualquer subordinação hierárquica ou funcional, e só sujeitos aos controles constitucionais de um poder pelo outro. MEIRELLES, Hely Lopes. Direito administrativo brasileiro. 25. ed. São Paulo: Malheiros, 2000. p. 65. 
com os dispositivos legais que regem a Administração Pública. Caso seja verificada qualquer ilegalidade, o TCU é legitimado para determinar ao responsável pela ação, em prazo estipulado pela própria Corte de Contas, a adoção de providências no sentido de sanar a ilegalidade. Dessarte, o Tribunal terá competências, ao verificar a ocorrência de ilegalidades na prestação dos serviços públicos, para assinar prazo para que o gestor adote providências para a correção da norma transgredida.

Esses são, basicamente, os dispositivos que dão suporte para atuação do Tribunal de Contas da União no controle dos serviços públicos concedidos e permitidos. A forma como a Corte de Contas vai utilizá-lo para desempenhar as suas funções constitucionais será vista adiante.

\section{Serviços públicos}

\subsection{Definição do termo}

A tarefa de definir o que vem a ser serviço público não é das mais fáceis. Carvalho Filho ${ }^{3}$ aponta que "[...] constitui traço de unanimidade na doutrina a dificuldade de definir, com precisão, serviços públicos”.

A conceituação do termo serviço público é algo tão complicado que nem mesmo o legislador ordinário se atreveu a fazê-la. A Lei no 8.987, de 13 de fevereiro de 1995, que dispõe sobre o regime de concessão e permissão da prestação de serviços públicos, apresenta a conceituação de diversos termos: poder concedente, concessão de serviço público, concessão de serviço público precedida da execução de obra pública e permissão de serviço público. A norma se omite, contudo, por não definir "serviço público".

${ }^{3}$ CARVAlHO FILHO, José dos Santos. Manual de direito administrativo. 14. ed., rev. e ampl. Rio de Janeiro: Lumen Juris, 2005. p. 259. 
No direito alienígena, a matéria é tratada da mesma maneira. Bielsa ${ }^{4}$ informa que "[...] tanto en el dominio del derecho administrativo como en el de la ciencia de la administración, no hay, quizá, idea o noción más imprecisa que la relativa al servicio público."

Helly Lopes Meirelles ${ }^{5}$ se posicionava no mesmo sentido:

O conceito de serviço público não é uniforme na doutrina, que ora nos oferece uma noção orgânica, só considerando como tal o que é prestado por órgãos públicos; ora nos apresenta uma conceituação formal, tendente a identificá-lo por características extrínsecas; ora nos expõe um conceito material, visando a defini-lo por seu objeto. Realmente o conceito de serviço público é variável e flutua ao sabor das necessidades e contingências políticas, econômicas, sociais e culturais de cada comunidade, em cada momento histórico, como acentuam os modernos publicistas.

A amplitude do termo fica bem caracterizada nas palavras de La Torre: ${ }^{6}$

Il termine "servizio pubblico" há varii significati. Anzitutto, in senso latissimo e improprio, si può intendere per servizio pubblico qualsiasi branca dell'attività dell'amministrazione (servizio giudiziario, servizi di sicurezza, ecc.) anche per quanto concerne la cosidetta attività giuidica. In senso proprio e intermedio, si qualificano servizi pubblici i servizi istituiti da una pubblica Amministrazione per immediato vantaggio del pubblico, ossia per la generalità dei cittadini che si trovino nelle condizioni per richiedere Il servizio stesso.

A mesma compreensão é apresentada por Vedel: ${ }^{7}$

4 BIELSA, Rafael. Ciencia de la administracion. Rosario: Universidad Nacional del Litoral, 1937.

5 MEIRELLES, Hely Lopes. Direito administrativo brasileiro. 25. ed. São Paulo: Malheiros, 2000. p. 306.

${ }^{6}$ LA TORRE, Michele. Nozione di diritto amministrativo. Roma: Stamperia Reale di Roma, 1935. p. 236.

7 VEDEL, M. Georges. Cours d'institutions administratives. Paris: Les Cours de Droit, 19611962. p. 263-264. 
On sait la place quà partir de la fin du XIXème siècle, le droit administratif a fait à la notion de service public au point que nombre d'auteurs ont vu dans celeui-ci la pierre angulaire du droit administratif. On sait aussi la crise que la notion de service public a subie dans les anées 1950. L'on sait aussi quelle contre-attaque vigoureuse les tenants du service public et, dernièrement, notamment $M$. le Président de Latournerie, dans "Etudes et Documents du Conseil d'Etatat", ont conduite en faveur de la notion qui leur est chère. Ces vicissitudes de la doctrine juridique ne sont pas notre sujet. On voudrait simplement faire remarquer que si, en l'état actuel de choses, Il nest pas possible de donner une définition précise du service public, c'est parce que cette définition ne se trouve nulle part.

Sans doute, comme on a déjà eu l'occasion de le dire, aux origines, la notion de service public était relativement nette, grace à l'utilisation du double critère fonctionnel, le service public était une activité de prestations destinées à satisfaire certains besoins jugés fondamentaux. Au point de vue organique, le service public était un enesemble de moyens pris en charge par l'Etat ou les collectivités publiques.

On sait comment, à partir du moment où, des deux critères, le critère organique s'effaça, c'est-à-dire à partir du moment où l'on admit qu'il existait des services publics virtuels qui pouvaient être gérés par de simples particuliers, la notion devint incontestablement plus fuyante.

A definição, portanto, do que vem a ser serviço público vem sofrendo grande variação ao longo da história. Desde a mais remota organização da sociedade em Estado, tem-se notícia da prestação de serviços direcionados ao público. Para os fins deste trabalho, será adotada como marco temporal a Revolução Francesa.

Sobre o tema, Dinorá Adelaide Musetti Grotti ${ }^{8}$ assevera que “[...] foi após a Revolução Francesa que a noção de serviço público apareceu no sentido da concepção que hoje entendemos. Não afasta, contudo, a possibilidade de terem existido atividades análogas antes desse período.”

8 GROTTI, Dinorá Adelaide Musetti. Teoria dos serviços públicos e sua transformação. In: SUNDFELD, Carlos Ari (Coord.). Direito administrativo econômico. São Paulo: Malheiros, 2002. p. 40. 
O tipo de Estado também influencia muito na definição de serviço público, pois os tipos de serviços prestados em Estado Liberal não serão os mesmos em Estado Social. Dromi ${ }^{9}$ considera que:

A evolução do conceito de serviço público está determinada por dois momentos históricos da vida econômica do Estado: o da economia liberal e da economia social.

O serviço público no Estado liberal do século XIX era alheio aos interesses coletivos da sociedade. Por isso, foi deixada na mão dos particulares a satisfação desses interesses e necessidades, limitando-se o Estado a uma função meramente orientadora e de polícia.

As profundas mudanças sociais e econômicas posteriores levaram a uma progressiva e necessária intervenção estatal, não somente regulamentando a prestação dos serviços, mas também assumindo diretamente sua gestão e execução.

Com efeito, a análise de qualquer definição terá que ser feita levando-se em consideração essas variáveis.

Nada obstante, é quase unânime entre os administrativistas que o estudo do tema deve ser iniciado pela escola francesa de serviços públicos. Dessa escola, destacam-se três grandes autores: Léon Duguit, Gaston Jèze e Maurice Hauriou.

O serviço público já foi entendido como a noção capital de todo o Direito Administrativo. Duguit sustentava a ideia de que o Estado funcionava como uma coordenação de serviços públicos.

O francês Léon Duguit apresentava em sua obra uma nova visão para o Direito Público. Com forte influência sociológica, foi severo crítico das teorias existentes do direito e pelo estabelecimento da noção de serviço público como fundamento do Estado e seu limite.

9 DROMI, Roberto. Derecho administrativo. 5. ed. Buenos Aires: Ciudad Argentina, 1996. p. 530 . 
Para Duguit, o Estado não era, como se queria fazer e como se acreditava há algum tempo, um poder que comandava uma soberania; ele era uma cooperação de serviços públicos organizados e controlados pelos governantes.

O jurista francês trouxe a seguinte definição para serviço público: ${ }^{10}$

É toda atividade cuja realização deva ser regulada, assegurada e controlada pelos governantes porque a realização dessa atividade é indispensável para a realização e o desenvolvimento da interdependência social e, por sua natureza, só pode ser completamente assegurada através da intervenção da força governante.

Mônica Spezia Justen ${ }^{11}$ considera que "Duguit aderiu o método do positivismo sociológico, segundo o qual o direito aplicável seria aquele socialmente aceito e integrado ao comportamento social.” Essa racionalidade social (e histórica) seria, quando decifrada pela sociedade e em especial pelos juristas, a fonte de um direito objetivo "[...] capaz de orientar a atividade legislativa no sentido da realização da solidariedade social.”

De acordo com essa definição, o desenvolvimento da sociedade levava à demanda de novos serviços públicos, que proporcionavam mais desenvolvimento para a sociedade, que, por conseguinte, levava à demanda de novos serviços públicos.

Duguit considerava que, quanto mais a sociedade se desenvolvia, maior era o número de atividades que poderiam servir de apoio aos serviços públicos. Dessa forma, o número de serviços considerados públicos sempre tenderia a aumentar. Somente três eram os serviços públicos legítimos na ótica do mestre francês: a defesa de toda a coletividade contra o inimigo externo; o serviço de polícia; e o serviço de justiça.

${ }^{10}$ DUGUIT, Léon. Traité de droit constitutionnel. 2. ed. Paris: Ancienne Librairie Fontemong \& Cie, 1923. p. 55.

${ }^{11}$ JUSTEN, Mônica Spezia. A noção do serviço público no direito europeu. São Paulo: Dialética, 2003. 
Essa linha de pensamento foi seguida por Malezieux, ${ }^{12}$ conforme se pode constatar na seguinte passagem:

En première approximation on peut définir le service public une enterprise d'intérêt général fonctionant sous la direction et sous le contrôle de l'Etat ou d'une collectivité publique.

Les pouvoirs publics, estimant que certaines activités présentent pour la communauté um intérêt tout particulier décident de conférer à cette activité la qualité se service public, de manière à lui assurer des conditions de fonctionnement sùres et stables.

Les motifs pour lesquels sont ainsi créés des services publics peuvent d'ailleurs être très variables. Ce peut être tout d'abord la nécessité d'assurer le fonctionnement d'une enterprise qui, par nature, n'est pás rentable. Par exemple, l'attribution de secours aux indigents est une enterprise dont aucun simple particulier ne pourrait se charger. La création d'une service public peut également des services publics qui ont pour objet de rapporter de l'argent aux collectivités publiques.

Les motifs qui poussent les collectivités publiques à crêer des services publics, pas plus que la nature même de l'enterprise n'intéressent en principe le juriste. Il s'agit là d'une question politique que seules des organes politiques ont qualité pour trancher. Le juriste et le juge ne doivent, en principe, que tirer les conséquences des termes de la loi.

Gaston Jèze, sucessor de Duguit na Escola de Bordeaux, também entendeu o Direito Administrativo como o conjunto das regras relativas aos serviços públicos, tanto os diretamente explorados pelo Estado, como os concedidos pelo Poder Público.

A despeito de figurar ao lado de Duguit como membro da escola do serviço público, porquanto consideram que o Direito Administrativo se explica a partir do conceito de serviço público, Gaston Jèze discorda de seu predecessor quanto à concepção objetiva de serviço público. Jèze considerava que essa concepção era

\footnotetext{
${ }^{12}$ MALEZIEUX. Raymond. Manuel de droit administratif. Paris: Cujas, 1954. p. 166-7.
} 
demasiadamente vaga, necessitando, portanto, de uma definição jurídica mais precisa. Com efeito, propôs que o tema fosse revisto sob uma concepção subjetiva.

Sobre o tema, Spezia Justen ${ }^{13}$ sustenta que:

Segundo essa ótica, poder-se-ia reconhecer na vontade do legislador ou do governante a intenção de eleger uma determinada necessidade de interesse geral à categoria de serviço público. Esse pensamento pode ser sintetizado pelas próprias palavras do autor: "Fala-se única e exclusivamente de serviços públicos quando as autoridades de um país, em determinada época, decidem satisfazer as necessidades de interesse geral mediante o procedimento de serviço público." Com a preocupação de reconhecer um serviço público, sem que pairassem dúvidas sobre sua natureza, Jèze manifestou-se firmemente no sentido de se averiguar a "intenção dos governantes".

Contemporâneo e compatriota de Duguit, Maurice Hauriou muito contribuiu para o estudo do serviço público. Marcello Caetano ${ }^{14}$ informa que foi Hauriou quem, na escola francesa do começo do século XIX, pôs em relevo a importância do serviço público como serviço técnico prestado ao público de maneira regular e contínua para satisfazer a ordem pública e por uma organização pública.

\subsection{Serviços públicos delegados.}

A noção de serviço público, como dito anteriormente, variou bastante desde a época da "Escola do Serviço Público". A seguinte passagem de Bandeira de Mello traduz bem esse pensamento: ${ }^{15}$

Durante algum tempo a noção de serviço público esteve ligada a um determinado tipo de atividade material

${ }^{13}$ JUSTEN, Mônica Spezia. A noção do serviço público no direito europeu. São Paulo: Dialética, 2003. p. 43.

${ }^{14}$ CAETANO, Marcello. Princípios fundamentais do direito administrativo. Coimbra: Almedina, 1996.

${ }^{15}$ MELlO, Celso Antônio Bandeira de. Curso de direito administrativo. São Paulo: Malheiros, 2006. p. 635. 
(serviços indispensáveis "à interdependência social, de tal modo que não poderiam ser prestados senão com a intervenção da força governante", cf. Duguit), época em que podia, razoavelmente servir como critério de repartição de competências entre as duas jurisdições existentes na França (comum e administrativa), pois se lhe atribuía o caráter de elemento decisório para a aplicação do Direito Administrativo. Veio a ser depois utilizada também para batizar outros tipos de atividades que o Estado passou a assumir (exploração de atividade econômica), sob o regime de direito privado, até mesmo para abarcar atividades exercidas por particulares, sem concessão, mas que se entendeu deveriam estar sob impacto de regras publicísticas ("serviço público virtual").

Marcello Caetano ${ }^{16}$ distingue os serviços públicos por meio de três critérios: o do objeto, o da retribuição e o do modo de gestão. Quanto ao objeto, distinguem-se os serviços públicos econômicos (produção e distribuição de água, de energia elétrica, transporte coletivo etc.), sociais ou de segurança social (previdência, assistência social, saúde etc.) e os culturais (escolas, museus, bibliotecas etc.).

A prestação dos serviços públicos econômicos constitui uma forma de intervenção do Estado na economia. Isso ocorre na medida em que o Estado acaba por realizar atividades que, em princípio, poderiam ser plenamente supridas pelo mercado. A prestação de serviço de transporte coletivo, por exemplo, poderia seguir a regra básica da oferta $\mathrm{x}$ demanda, tais quais os serviços prestados por um pintor.

Se o Estado, no entanto, deixasse a prestação do serviço de transporte público exclusivamente na mão dos particulares, poderia ocorrer a falta da prestação desse serviço onde o fluxo de passageiros não trouxesse boa rentabilidade. Existem setores da economia que o mercado não possui interesse em atuar. Por exemplo, a distribuição de energia elétrica para um povoado ribeirinho da Amazônia. Não se pode esquecer que a força motriz do mercado é a obtenção do lucro, razão pela qual nas atividades que não apresentam boas perspectivas de retorno, não haverá interesse da iniciativa privada.

${ }^{16}$ CAETANO, Marcello. Princípios fundamentais do direito administrativo. Coimbra: Almedina, 1996. p. 218. 
Cumpre deixar claro que existem diversas formas de intervenção do Estado na economia. Em apertada síntese, tendo como parâmetro a Constituição Federal, pode-se dividir o assunto em três grandes áreas: a exploração direta da atividade econômica pelo Estado (art. 173); a normatização e regulação da atividade econômica pelo Estado (art. 174); e a prestação de serviços públicos diretamente pelo Estado ou sob o regime de concessão ou permissão (art. 175).

A evolução da forma como os serviços públicos vêm sendo prestados, em verdade, demonstra a preocupação com que o Estado tem em adaptar-se à modernidade, ao gerenciamento eficiente de suas atividades e ao fenômeno da globalização.

A partir da segunda metade do século XX, a quase totalidade dos países ocidentais passou por diversas mudanças no cenário econômico. Ao final da Segunda Grande Guerra, o mundo foi dividido, basicamente, em dois grandes blocos: o dos países capitalistas, capitaneados pelos Estados Unidos da América, e o dos países socialistas, liderados pela União das Repúblicas Socialistas Soviéticas. A competição entre eles ia muito além da questão bélica. Havia a necessidade de demonstrar para o restante do mundo que a forma de Estado adotada era a que trazia maiores benefícios para a coletividade. Em razão disso, os governos não economizavam para realizar o bem-estar social, o que implicava aumento das atividades do Estado, que passou a agir em atividades dantes exclusivas da iniciativa privada. Com o passar do tempo, esse modelo ficou custoso a ponto de não poder ser suportado pelos governos. A partir de então, foi necessário repensar as atividades desenvolvidas pelo Estado.

Para ilustrar essa situação, vale trazer a lume excerto do prefácio da publicação Private Participation in Infrastructure: Trends in Developing Countries in 19902001, de autoria do Banco Mundial. ${ }^{17}$

For most of the 20th century developing countries looked to their public sectors as the exclusive financiers and operators of infrastructure services. Too often, however, the results proved disappointing. State-owned monopolies were typically

${ }^{17}$ BANCO MUNDIAL. Private participation in infrastructure: trends in developing countries in 1990-2001: energy, telecomunications, transport, water. Washington: World Bank, 2003. p. 10. 
charged with multiple objectives, subject to relentless political interference, and plagued by inefficiency. Infrastructure prices in particular tended to be driven by short-term political considerations, often resulting in inadequate revenues even to maintain services, let alone finance service expansions. Costs of technical inefficiency and mispricing were large relative to total public investment.

By the late 1980s growing frustration with those problems, coupled with budget constraints, led to a search for alternatives. Reflecting positive experience in Chile and the United Kingdom, the key feature of the new approach was for the state to focus on its role as a policymaker and a regulator and to delegate the financing and operation of services to private firms.

Como visto, algumas atividades desenvolvidas diretamente pelo Estado foram transferidas para as mãos da iniciativa privada. A década de 1990, no Brasil, foi marcada pela desestatização dessas atividades.

A desestatização, consoante previsto na Instrução Normativa/TCU no 27, de 2/12/1998, pode ser entendida como a transferência para a iniciativa privada, de participações societárias e da execução dos serviços públicos explorados pela União por intermédio das entidades da Administração Pública Federal. A desestatização pode se dar por meio da privatização, que é a alienação pela União de direitos que lhe assegurem, diretamente ou por meio de outras controladas, preponderância nas deliberações sociais e poder de eleger a maioria dos administradores da sociedade. Exemplo de privatização ocorreu com a mineradora Vale do Rio Doce. Outra forma de desestatização é a delegação da prestação de serviços públicos, por meio de concessão ou permissão, mediante licitação, à pessoa jurídica ou consórcio de empresas que demonstre capacidade para seu desempenho, por sua conta e risco e por prazo determinado.

Não constitui objetivo deste trabalho estudar a diferenciação entre os termos concessão e permissão. Nada obstante, vale trazer à baila o entendimento sobre o tema contido na citada Instrução Normativa nº 27 , do Tribunal de Contas da União: ${ }^{18}$

\footnotetext{
${ }^{18}$ BRASIL. Instrução Normativa/TCU nº 27, 2 dez. 1998. Dispõe sobre a fiscalização pelo Tribunal de Contas da União dos processos de desestatização. Disponível em: <http://www.tcu.gov.br/ Consultas/ Juris/Docs/judoc/IN/20090624/INT1998-027.doc.> Acesso em: 17 fev. 2010.
} 
Concessão de serviço público: a delegação de sua prestação, feita pelo poder concedente, mediante licitação, à pessoa jurídica ou consórcio de empresas que demonstre capacidade para seu desempenho, por sua conta e risco e por prazo determinado (art. $1^{\circ}, \$ 1^{\circ}$, inciso III);

Permissão de serviço público: a delegação, a título precário, mediante licitação, da prestação de serviços públicos, feita pelo poder concedente à pessoa física ou jurídica que demonstre capacidade para seu desempenho, por sua conta e risco (art. $1^{\circ}, \S 1^{\circ}$, inciso $\mathrm{V}$ ).

A título de ilustração, segue o conceito do termo concessão apresentado pelos professores Guido Landi e Giuseppe Potenza para o direito italiano: ${ }^{19}$

Concessione - cioè in un atto amministrativo negoziale mediante il quale la pubblica amministrazione conferisce ad un privato l'esercizio d'un servizio pubblico. Tale ipotesi con frequenza si riscontra in materia di transporti (concessione di ferrovie, di linee automobilistiche, di linee di navigazione marittima o aerea); di comunicazioni (concessioni telefoniche), etc. Sono inoltre servizi gestititi in regime di concessione (per quanto impropriamente si parli nella pratica di appalto) quelli di riscossione delle imposte dirette, nonchè delle "imposte di consumo" dovute ai Comuni.

Lattività svolta dal concessionario ha carattere privato; è svolta cioè nel suo interesse ed a fine di lucro, sebbene egli possa essere investito, per le esigenze del servizio, del potere di compiere taluni atti d'autorità, quali verbalizzazioni, contestazioni di contravvenzioni, etc.

\section{0 controle do tribunal de contas da união nos serviços públicos delegados}

Em geral, os serviços públicos delegados são controlados pelas agências reguladoras, que, atualmente, assumiram esse papel dantes exercido pela administração pública direta, na qualidade de poder concedente.

${ }^{19}$ LANDI, Guido; POTENZA, Giuseppe. Manuale de diritto amministrativo. Milano: D. A. Giuffrè, 1963. p. 81. 
As agências reguladoras, consoante as leis específicas que as criaram, possuem natureza jurídica de autarquias. Assim, são pessoas jurídicas de direito público, que, por força do art. 37, inciso XIX, da Constituição Federal, somente podem ser criadas por lei específica. Ademais, exercem atividades e serviços administrativos, possuem autonomia patrimonial e estão sob o controle e a tutela do Estado quanto à sua organização, administração e fiscalização.

Acerca da natureza jurídica e competências das agências reguladoras, vale trazer à baila as palavras de Zymler e Almeida: ${ }^{20}$

\begin{abstract}
Aduz-se que, sopesada sua significativa autonomia, as agências reguladoras são autarquias especiais, dotadas de competência para regulamentar, contratar, fiscalizar, dirimir conflitos, aplicar sanções, e zelar pelos direitos dos usuários de serviços públicos ou atividades econômicas relevantes. A fundamentação de seu caráter especial é ressaltada em alguns normativos, como se constata no $\$ 2^{\circ}$ do art. $8^{\circ}$ da Lei n. 9.472/1997, o qual estabeleceu que "a natureza da autarquia especial conferida à Agência é caracterizada por independência administrativa, ausência de subordinação hierárquica, mandato fixo e estabilidade de seus dirigentes e autonomia financeira.
\end{abstract}

Pelo exposto, é fácil perceber que as agências reguladoras possuem importante papel no controle dos serviços públicos concedidos e permitidos. Pode-se, inclusive, afirmar que foram criadas justamente com o intuito de serem as grandes fiscalizadoras desses serviços. Para tanto, possuem competência para dirimir conflitos, aplicar sanções e, por vezes, emitir atos administrativos normativos.

Uma vez que o escopo deste trabalho não é o controle exercido pelas agências reguladoras, as suas idiossincrasias deixarão de ser aprofundadas, para que se possa concentrar no papel exercido pelo Tribunal de Contas da União.

Às agências reguladoras, por serem autarquias especiais, aplicam-se todas

\footnotetext{
${ }^{20}$ ZYMLER, Benjamin; ALMEIDA, Guilherme Henrique de La Rocque. O controle externo das concessões de serviços públicos e das parcerias público-privadas. Belo Horizonte: Fórum, 2005. p. 53-54.
} 
as normas que disciplinam a administração pública. Por conseguinte, devem respeitar as leis que tratam da realização das receitas e despesas públicas.

Na realização dessas despesas, submetem-se aos mesmos tipos de controle que os demais órgãos da administração pública. Assim sendo, por força do art. 71, inciso II, da Constituição Federal devem prestar contas ao Tribunal de Contas da União.

Com efeito, na execução das tarefas relacionadas com suas competências ordinárias, as agências reguladoras submetem-se ao crivo do Tribunal de Contas da União. Ocorre que o intuito deste trabalho não é demonstrar o controle exercido nas agências reguladoras e sim nos serviços públicos concedidos e permitidos.

Pelo que até o presente momento foi colocado, tem-se que as agências reguladoras exercem controle sobre os ditos serviços públicos concedidos e permitidos e que o Tribunal de Contas da União exerce o controle sobre as agências reguladoras. A dúvida que remanesce é se o TCU pode realizar o controle diretamente sobre os concessionários e permissionários e, em caso afirmativo, de que forma deve proceder.

Para melhor compreensão do tema, é pertinente dividi-lo em duas etapas: a primeira relaciona-se com o controle da concessão ou da permissão propriamente dita, ou seja, do ato que o Estado entrega ao particular a possibilidade de prestar os serviços públicos. A segunda refere-se ao controle da execução da prestação dos serviços.

Vale esclarecer que, para os fins deste trabalho, doravante, optou-se por utilizar somente o termo concessão, porquanto a atuação do Tribunal de Contas da União, em geral, independe da forma a ser utilizada na delegação do serviço público, seja concessão ou permissão.

Consoante mencionado alhures, a concessão é uma espécie de desestatização, que, em apertada síntese, pode ser entendida como a passagem de um patrimônio público para o particular. Assim, tem-se que, em um primeiro momento, o serviço era prestado diretamente pelo Estado, que se beneficiava, por óbvio, dos lucros advindos dessa prestação. Com a concessão, os serviços são delegados a um particular que irá se beneficiar dos lucros gerados. 
Essa passagem do Estado para o particular deve ser feita por meio de regras, uma vez que qualquer pessoa pode ter o interesse de realizar a prestação do serviço. Ademais, o Estado deve receber uma contraprestação justa, a fim de compensar as receitas que não mais ingressarão nos cofres públicos.

O caput do art. 70 da Constituição Federal submete o procedimento de concessão ao controle externo. Eis o texto da carta política:

Art. 70. A fiscalização contábil, financeira, orçamentária, operacional e patrimonial da União e das entidades da administração direta e indireta, quanto à legalidade, legitimidade, economicidade, aplicação das subvenções e renúncia de receitas, será exercida pelo Congresso Nacional, mediante controle externo, e pelo sistema de controle interno de cada Poder.

O dispositivo, ao mencionar a fiscalização patrimonial, concede competência para o Tribunal de Contas da União, por ser órgão que presta auxílio ao Congresso Nacional no exercício do controle externo, realizar a fiscalização das ditas concessões. Esse raciocínio decorre do fato de a desestatização, da qual a concessão é espécie do gênero, ser caracterizada como a passagem de um patrimônio pertencente ao Estado para um particular,

A forma de atuação do Tribunal de Contas da União no controle dos processos de desestatização está disciplinada na já mencionada Instrução Normativa no 27 , de $2 / 12 / 1998$.

A título de ilustração, vale trazer à baila a ementa do Acórdão nº 68/2003, do Plenário do Tribunal de Contas da União, publicado no Diário Oficial da União em 25/2/2003, que apreciou a legalidade da quarta rodada de licitações de blocos para a concessão das atividades de exploração, desenvolvimento e produção de petróleo e gás natural, cujo relator foi o Ministro Ubiratan Aguiar. ${ }^{21}$

ACOMPANHAMENTO. AGÊNCIA NACIONAL DE PETRÓLEO - ANP. CONCESSÃO DAS ATIVIDADES DE

${ }^{21}$ TRIBUNAL DE CONTAS DA UNIÃO. Acórdão 68/2003-TCU-Plenário. Disponível em: $<\mathrm{http}$ // contas.tcu.gov.br/portaltextual/MostraDocumento ?qn=1\&doc=2\&dpp=20\&p=0>. Acesso em: 17 fev. 2010. 
EXPLORAÇÃO, DESENVOLVIMENTO E PRODUÇÃO DE PETRÓLEO E GÁS NATURAL. QUARTA RODADA DE LICITAÇÕES. ESTÁGIOS 1, 2 E 3. INTEMPESTIVIDADE NA APRESENTAÇÃO DOS DOCUMENTOS RELATIVOS AO PROCESSO. FRAGILIDADE DO ESTUDO DE VIABILIDADE TÉCNICA E ECONÔMICA DOS BLOCOS LICITADOS. ADOÇÃO DE CRITÉRIOS DE SELEÇÃO DE BLOCOS SEM A DEMONSTRAÇÃO DE QUE OBSERVAM A POLÍTICA ENERGÉTICA NACIONAL. APROVAÇÃO COM RESSALVAS. DETERMINAÇÃO.

A análise da referida ementa permite verificar que o Tribunal de Contas da União realiza controle sobre a forma como o procedimento de concessão está transcorrendo. Pode-se perceber que tanto aspectos formais como materiais são levados em consideração na apreciação da Corte de Contas Federal. Na apreciação em tela, o TCU informa que houve atraso no envio àquela Corte dos documentos relativos ao processo licitatório de concessão: falha de natureza forma que pode prejudicar a análise a ser efetuado pelo Tribunal. Apontou, ainda, fragilidade do estudo de viabilidade técnica e econômica dos blocos licitados. Ou seja, o TCU considerou que os estudos apresentados pelo órgão concedente não eram robustos o suficiente para justificar o valor a ser cobrado pelo objeto licitado.

Em outra oportunidade, o Plenário do TCU, por meio do Acórdão no 102/2007, publicado no Diário Oficial da União em 9/2/2007, analisou o processo de outorga da subconcessão onerosa da administração e exploração do serviço público de transporte ferroviário, com arrendamento, por período de 30 (anos), do trecho da Ferrovia Norte-Sul (FNS) entre Açailândia/MA e Palmas/TO, numa extensão total de $720 \mathrm{~km}$ e faixa de domínio de $40 \mathrm{~m}$ de cada lado a partir de seu eixo, concedido à Valec Engenharia Construções e Ferrovias S.A., empresa estatal vinculada ao Ministério dos Transportes. Segue a referida ementa ${ }^{22}$

ACOMPANHAMENTO DO PROCESSO DE SUBCONCESSÃO DE TRECHO FERROVIÁRIO. ANÁLISE DA DOCUMENTAÇÃO ALUSIVA AOS $1^{\circ}$ E $2^{\circ}$ ESTÁGIOS A QUE SE REFERE À INSTRUÇÃO NORMATIVA TCU No

22 TRIBUNAL DE CONTAS DA UNIÃO. Acórdão 102/2007-TCU-Plenário. Disponível em: <http://contas.tcu.gov.br/portaltextual/ MostraDocumento?qn=2\&doc=1\&dpp=20 $\& \mathrm{p}=0>$. Acesso em: 17 fev. 2010. 
27/1998. IDENTIFICAÇÃO DE INCONSISTÊNCIAS NOS ESTUDOS DE VIABILIDADE E FALHAS NO EDITAL LICITATÓRIO E NA MINUTA DO CONTRATO. AUTORIZAÇÃO PARA CONTINUIDADE DO PROCESSO DE OUTORGA, CONDICIONADA À CORREÇÃO DAS INCONSISTÊNCIAS E FALHAS DETECTADAS NOS REFERIDOS DOCUMENTOS. DETERMINAÇÕES. CIÊNCIA A DIVERSOS ÓRGÃOS E ENTIDADES. RESTITUIÇÃO DOS AUTOS À SEFID.

Para melhor compreensão da ementa, convém esclarecer que a Instrução Normativa TCU no 27/1998 estabelece que os $1^{\circ}$ e $2^{\circ}$ estágios de fiscalização dos processos de concessão têm por objetivo verificar se os órgãos concedentes estão respeitando as premissas básicas da modelagem de desestatização e da viabilidade técnica, econômica e ambiental do trecho a ser outorgado, assim como verificar se o edital de licitação e a minuta de contrato que o acompanha estão consonantes com as disposições contidas na Lei n 8.987, de 1995 e na Lei no 8.666, de 1993. Importa, também, explicitar que "SEFID” é a Secretaria de Fiscalização de Desestatização do Tribunal de Contas da União, unidade técnica responsável pela análise inicial do processo.

No presente caso, a decisão do TCU condicionou o prosseguimento da licitação à correção de inconsistências encontradas pela Corte de Contas. Da leitura do voto do Ministro-Relator, pode-se perceber que o Tribunal encontrou falhas relacionadas tanto no valor da concessão, como na operacionalização do certame. A seguinte passagem é capaz de demonstrar a preocupação da Corte de Contas com o valor do certame:

21. Utilizando as mesmas premissas e os mesmos dados constantes dos estudos apresentados pela CAF [Corporação Andina de Fomento - CAF, entidade contratada pelo Governo Federal, por meio do Ministério do Planejamento, Orçamento e Gestão, para prestar assistência na avaliação da viabilidade financeira do projeto de expansão da FNS e no desenho de uma estrutura factível de ser executada e/ ou operada pelo setor privado] e pela Valec, a Sefid, sem adentrar no mérito dos valores adotados, encontrou uma estimativa da taxa de desconto para o projeto da Ferrovia Norte-Sul da ordem de $8,52 \%$, valor significativamente diferente dos 12,75\% estimados pela Valec. 
22. Segundo esclarece a Unidade Técnica, a estimativa da taxa de desconto deve ser calculada a partir dos métodos disponíveis de avaliação de ativos e, para se evitar grande discrepância de análise, é fundamental que a metodologia de cálculo adotada seja robusta, compatível e consistente com a literatura econômica e com a praticada no mercado financeiro.

23. Releva destacar, como demonstrado nos autos, que a redução da estimativa da taxa de desconto efetivada pela Valec não redundou, como seria o esperado, em alteração do valor mínimo de outorga, pois, concomitantemente à essa alteração, referida empresa reavaliou a produção prevista para o período de 2007 a 2010 para baixo, gerando uma perda de receita, que, por sua vez, compensou o aumento esperado no valor mínimo de outorga proporcionado pela correção da taxa de desconto.

24. A Sefid concluiu o exame desse ponto consignando que as alterações efetivadas pela Valec tiveram o objetivo de manter a taxa de desconto adotada inicialmente no estudo econômico-financeiro; a falta de consistência técnica das alterações promovidas pela Valec no cálculo do custo do capital torna questionável o estudo de avaliação econômicofinanceira do projeto para a Ferrovia Norte-Sul; e, levando em consideração, estritamente, sem avaliar o mérito, os dados e as informações disponibilizados pela CAF e pela Valec, em termos econômicos, o valor mínimo de outorga de licitação da Ferrovia Norte-Sul estaria subavaliado.

As falhas operacionais do certame licitatório foram apontadas no seguinte excerto do voto:

31. Uma das principais falhas verificadas refere-se à inserção de inúmeras cláusulas incumbindo à Valec, mesmo depois de realizada a subconcessão e concluída a construção dos trechos ferroviários a seu cargo, de diversas obrigações e direitos relacionados à administração, à exploração da FNS e à fiscalização do contrato de subconcessão nos moldes de um ente regulador, contrariando o disposto na Lei $n^{\circ} 10.233 / 2001$ e na Lei no 8.987/1995.

32. Ressalto que, de acordo com o disposto no art. $26, \$ 2^{\circ}$, da Lei $\mathrm{n}^{\circ} 8.987 / 1995$, o subconcedente sub-rogará todos os direitos e as obrigações da concessão ao subconcessionário, dentro dos limites da subconcessão. Nesse sentido, a subconcessionária assumirá o que dispõe o contrato de concessão firmado entre a ANTT e a Valec no que pertine à administração e à exploração do trecho da FNS compreendido entre Açailândia/ MA e Palmas/TO, desfazendo-se todos os vínculos entre a 
Valec e a ANTT com relação ao objeto da subconcessão, e se relacionará diretamente com aquela agência.

33. Em conseqüência dessas cláusulas, a ANTT somente exercerá muitas das suas atribuições legais por intermédio da Valec.

34. Outra falha apurada pela Sefid refere-se à restrição, contida no parágrafo 45 do edital de licitação, à participação no certame a pessoas jurídicas brasileiras, inibindo o caráter competitivo da licitação e impedindo a observância do princípio constitucional da isonomia e a seleção da proposta mais vantajosa para a Administração, em infringência ao disposto no art. $3^{\circ}$, caput e $\$ 1^{\circ}$, inciso I, da Lei ${ }^{\circ}$ 8.666/1993.

35. Foi verificada, também, a inclusão, nos parágrafos 68 e 99 do edital, de exigência cumulativa de capital social mínimo e de apresentação de garantia de proposta, no valor referente a $1 \%$ do valor da outorga, em desacordo com o disposto no art. $31, \S 2^{\circ}$, da Lei no 8.666/1993.

36. Outra fragilidade identificada pela Sefid no edital de licitação refere-se à ausência de clareza, na cláusula vigésima terceira, item I, quanto à definição e à identificação dos bens reversíveis da subconcessão.

Os elementos ora apresentados afastam quaisquer dúvidas acerca da legitimidade do Tribunal de Contas da União de apreciar processos de concessão de serviços públicos. Remanesce, entretanto, a questão relacionada à possibilidade de o Tribunal realizar o controle diretamente sobre as concessionárias dos ditos serviços.

Em geral, as concessões de serviços públicos são regidas pela Lei nº 8.987, de 13/2/1995, que dispõe sobre o regime de concessão e permissão da prestação de serviços públicos previstos no art. 175 da Constituição Federal, e dá outras providências. Com efeito, as concessões são precedidas por um chamamento público, por meio de licitação, normalmente sob a forma de concorrência. Dessa competição, advém a assinatura de um contrato, que, de forma simplória, pode ser considerado como a "lei” da concessão.

As agências reguladoras, consoante já mencionado, possuem incumbência primária para fiscalizar se os serviços prestados pelas concessionárias estão de acordo com os preceitos legais e contratuais. 
Uma vez que as agências são fiscalizadas pelo Tribunal de Contas da União, poderia a Corte de Contas fiscalizar também as concessionárias prestadoras de serviços públicos? Para responder a essa questão, é necessário perscrutar as competências constitucionais conferidas ao TCU.

Concentrando-se no inciso IV do art. 71 da Constituição Federal, acima reproduzido, pode-se ver que o constituinte originário, dentre outras, concedeu competência para a Corte de Contas realizar auditorias de natureza operacional nos órgãos e entidades da Administração Pública. Sendo as agências reguladoras autarquias de natureza especial, elas, sem sombra de dúvidas, estão sujeitas a esse tipo de fiscalização.

De acordo com o portal do Tribunal de Contas da União na internet, ${ }^{23}$ a auditoria de natureza operacional tem como objetivo avaliar o desempenho das ações do Estado para atender às necessidades da sociedade. Por isso, também é chamada de auditoria de desempenho. Essa avaliação tem como focos principais a eficiência, a efetividade e a economicidade das intervenções governamentais. Objetiva contribuir para a melhoria do desempenho da ação de governo, bem como garantir informações fidedignas à sociedade e ao Parlamento sobre o desempenho dos programas e organizações governamentais com vistas à prestação de contas pelos seus resultados.

Em relação às agências reguladoras, visa o TCU, ao realizar auditorias de natureza operacional, verificar se estão sendo atingidas as finalidades decorrentes de sua criação, ou seja, se estão executando a contento as atividades de regulação e de fiscalização junto às empresas concessionárias.

Sobre o assunto, merecem ser trazidas a lume as palavras do Ministro do Tribunal de Contas da União Benjamin Zymler: ${ }^{24}$

${ }^{23}$ TRIBUNAL DE CONTAS DA UNIÃO. Auditoria de natureza operacional. Disponível em: $<$ http://portal2.tcu.gov.br/portal/page/portal/ TCU/comunidades/programas_governo/ historico $>$. Acesso em: 9 fev. 2010.

${ }^{24}$ ZYMLER, Benjamin. Direito administrativo e controle. Belo Horizonte: Fórum, 2005. p. 323-324. 
Dessa forma, impõe-se ao Tribunal a fiscalização da execução dos contratos de concessão. Uma análise superficial identificaria redundância das esferas de controle, uma vez que uma das atribuições das agências é exatamente fiscalizar os contratos de concessão e de permissão e os atos de autorização de serviços públicos.

Entretanto, fica claro que o TCU exerce uma atividade fiscalizatória de segundo grau, que busca identificar se as agências estão bem e fielmente cumprindo seus objetivos institucionais, dentre os quais o de fiscalizar a prestação de serviços públicos. Deve a Corte de Contas, no desempenho de sua competência constitucional, atestar a correção da execução desses contratos. Ressalte-se, todavia, que esta ação não visa a controlar a empresa concessionária em si, mas apenas examinar se as agências estão fiscalizando de forma adequada os contratos por elas firmados.

Não deve o Tribunal substituir as agências. Deverá, apenas, zelar pela atuação pronta e efetiva dos entes reguladores, para assegurar a adequada prestação de serviços públicos à população.

A jurisprudência do TCU é pacífica quanto à possibilidade de o Tribunal realizar o controle de segunda ordem nas concessionárias de serviço público. A título de ilustração, vale transcrever trecho do voto condutor do Acórdão n⿳o 1756/2004-Plenário, publicado no Diário Oficial da União em 23/11/2004²5:

25. Com fulcro nessas breves considerações, entendo ter ficado patente que o TCU possui competência para fiscalizar as atividades finalísticas das agências reguladoras. Entretanto, cumpre analisar a forma como o Tribunal deve atuar e os limites dessa atuação.

26. O TCU deve atuar de forma complementar à ação das entidades reguladoras no que concerne ao acompanhamento da outorga e da execução contratual dos serviços concedidos. Afinal, o fato de o Poder Concedente deter competência originária para fiscalizar a atuação das concessionárias não impede a atuação cooperativa e suplementar do TCU, que pode, assim, fiscalizar a prestação dos serviços públicos delegados. Por outro lado, a Corte de Contas não pode substituir o órgão regulador,

${ }^{25}$ TRIBUNAL DE CONTAS DA UNIÃO. Acórdão 1.756/2004-TCU-Plenário. Disponível em: <http://contas.tcu.gov.br/portaltextual/ MostraDocumento?doc $=5 \& \mathrm{p}=0 \& \mathrm{qn}=1 \&$ tem pl=default $>$. Acesso em: 24 nov. 2010. 
sob pena de atuar de forma contrária à Constituição Federal. Nesse sentido, cumpre reiterar que a fiscalização do Tribunal deve ser sempre de segunda ordem, sendo seu objeto a atuação das agências reguladoras como agentes estabilizadores e mediadores do jogo regulatório. Logo, essa fiscalização não deve versar sobre o jogo regulatório em si mesmo considerado. (grifo nosso).

Resta claro, portanto, que o Tribunal de Contas da União possui competência para exercer uma atividade fiscalizatória de segundo grau sobre os serviços públicos concedidos e permitidos. Em algumas ocasiões, a atuação do TCU foi primordial para o resguardo dos direitos dos usuários dos mencionados serviços públicos.

Como exemplo, pode-se citar o Acórdão no 2.154/2007 - TCU/Plenário, publicado no Diário Oficial da União em 15/10/200726, pelo qual a Corte determinou à Agência Nacional de Transportes Terrestres - ANTT que realizasse, “[...] no prazo de 30 dias, estudos com o objetivo de verificar se as atuais concessões de rodovias federais exploradas pelas concessionárias NovaDutra, Concer, CRT, Ponte Rio-Niterói e Concepa estão em equilíbrio econômico-financeiro, em razão da rentabilidade contratual - taxa interna de retorno do investimento (TIR).”

Em outro caso, o controle exercido pelo Tribunal demonstrou que, nos últimos sete anos, a população brasileira pagou em torno de R\$ 7.000.000.000,00 (sete bilhões de reais) de forma indevida às empresas de eletricidade. A constatação deveu-se a uma série de fiscalizações efetuadas em diferentes prestadoras de serviços públicos, em que foram detectadas inconsistências metodológicas no cálculo das tarifas de energia cobradas pelas concessionárias de energia elétrica. $\mathrm{O}$ Acórdão no 556/2004 - TCU/Plenário, publicado no Diário Oficial da União em $24 / 5 / 2004$, foi um dos que apontou a irregularidade, sendo sua ementa vazada nos seguintes termos ${ }^{27}$ :

${ }^{26}$ TRIBUNAL DE CONTAS DA UNIÃO. Acórdão 2.154/2007-TCU-Plenário. Disponível em: <http://contas.tcu.gov.br/portaltextual/ MostraDocumento?qn=3\&doc=2\&dpp=20 $\& \mathrm{p}=0>$. Acesso em: 17 fev. 2010.

27 TRIBUNAL DE CONTAS DA UNIÃO. Acórdão 556/2004-TCU-Plenário. Disponível em: $<\mathrm{http}: / /$ contas.tcu.gov.br/portaltextual/ MostraDocumento qn $=4 \& d o c=2 \& d p p=20 \& p=0>$. Acesso em: 17 fev. 2010. 
ACOMPANHAMENTO. ANEEL. PROCESSO DE REVISÃO TARIFÁRIA DA LIGHT SERVIÇOS DE ELETRICIDADE S.A. EXERCÍCIO DE 2003. INCONSISTÊNCIAS METODOLÓGICAS RELATIVAS AO CÁLCULO DO FATOR X. DESCONSIDERAÇÃO DO BENEFÍCIO FISCAL DECORRENTE DA DISTRIBUIÇÃO DE JUROS SOBRE O CAPITAL PRÓPRIO. FIXAÇÃ̃O DE REPOSICIONAMENTO TARIFÁRIO ACIMA DO DEVIDO. DETERMINAÇÃO. REMESSA DE CÓPIA AO CONGRESSO NACIONAL E INTERESSADOS.

\section{Conclusão}

O objetivo deste trabalho era demonstrar como o Tribunal de Contas da União atua na fiscalização dos serviços públicos concedidos e permitidos. De início, optou-se por delimitar o tema por meio da definição do termo serviço público. Na oportunidade, foi visto que, devido à evolução do instituto, apontar um conceito preciso para o termo não é tarefa das mais fáceis.

A prestação dos serviços públicos, a partir da segunda metade do século $\mathrm{XX}$, na quase totalidade dos países ocidentais, passou por severas modificações, principalmente, em decorrência da necessidade da diminuição do tamanho do Estado. Como foi visto, atividades dantes prestadas diretamente pela Administração Pública passaram às mãos dos particulares. Os termos concessão e permissão passaram a integrar o cotidiano dos cidadãos comuns.

A necessidade de fiscalizar e regulamentar como os serviços públicos estavam sendo prestados pelos concessionários e permissionários fez com que, no Brasil, fossem criadas as agências reguladoras, entidades integrantes da administração pública indireta sob a forma de autarquia especial.

Essas entidades, por gerirem recursos de natureza pública, estão, consoante preconizado no art. 71 da Constituição Federal, sujeitas à fiscalização do Tribunal de Contas da União. Dentre as fiscalizações exercidas pela Corte de Contas, uma em especial interessou ao presente trabalho: as auditorias de natureza operacional. 
É por meio desse tipo de fiscalização que o TCU pode realizar controle de segunda ordem nas empresas concessionárias e permissionárias de serviço público, uma vez que o controle de primeira ordem sempre fica a cargo das referidas agências.

A atuação da Corte cada vez mais se mostra essencial para o aprimoramento da prestação dos serviços públicos. Não foram poucas as vezes em que o TCU demonstrou haver desequilíbrio entre o preço cobrado dos usuários e a qualidade dos serviços prestados. Por outras, o Tribunal detectou que a exploração da atividade pelas empresas delegadas não se coadunava com o que havia sido firmado entre as partes, ou seja, a concessionária descumpria cláusulas contratuais. Para sanar esses problemas, o Tribunal de Contas da União, legitimado pelo art. $71 \mathrm{da}$ Constituição Federal, fixa prazo para que a irregularidade seja sanada, a fim de que o cidadão possa contar com serviço público digno e eficiente.

\section{The role of the brazilian court of audit in control of public services delegates}

\section{Abstract}

The present article aims to demonstrate the form of action the Brazilian Court of Audit in the control of public delegates. To achieve this objective, was conducted extensive research on the doctrinal term public service, at which one can conclude that there is not unanimity among the lawyer about the matter. The provision of public services that in the early twentieth century was almost entirely supported by the state, gradually transferring to private individuals, through delegation of the former to the latter. Among other factors that led to this transfer, was the need to reduce the size of the state in order to reduce the costs of administrative machinery. So that society was not prejudiced by the provision of public services of low quality, it was necessary to create organisms capable of regulating the relationship between citizens and agents delegates. In our legal system, such a task is in charge of regulatory agencies that perform the primary control over how services are being provided, noting, among other things, whether the public interest being 
served, and whether the fees charged are consistent with what was agreed upon at the concession made by the State. At the Court of Audit meets the call hold control of second order. Through this control the Court of Auditors is able to check whether the regulatory agencies are fulfilling their legal and constitutional, in order to protect the public interest and ensure the provision of efficient services to citizens. At the end, is necessary to say that this article was not public in any vehicle.

Keywords: Control. Public service. Delegation. Regulatory agencies. Brazilian court of audit.

\section{Referências}

BANCO MUNDIAL. Private participation in infrastructure: trends in developing countries in 1990-2001: energy, telecomunications, transport, water. Washington: World Bank, 2003.

BIELSA, Rafael. Ciencia de la administracion. Rosario: Universidad Nacional del Litoral, 1937.

BRASIL. Constituição da República Federativa do Brasil 1988. Disponível em: <http://www.planalto.gov.br/ccivil_03/Constituicao/Constituiçao.htm.>. Acesso em: 17 fev. 2010.

BRASIL. Instrução Normativa/TCU no 27, 2 dez. 1998. Dispõe sobre a fiscalização pelo Tribunal de Contas da União dos processos de desestatização. Disponível em: <http://www.tcu.gov.br/ Consultas/Juris/Docs/judoc/IN/20090624/INT1998-027. doc. $>$. Acesso em: 17 fev. 2010.

CAETANO, Marcello. Princípios fundamentais do direito administrativo. Coimbra: Almedina, 1996.

CARVALHO FILHO, José dos Santos. Manual de direito administrativo. 14. ed., rev. e ampl. Rio de Janeiro: Lumen Juris, 2005.

DROMI, Roberto. Derecho administrativo. 5. ed. Buenos Aires: Ciudad Argentina, 1996. 
DUGUIT, Léon. Traité de droit constitutionnel. 2. ed. Paris: Ancienne Librairie Fontemong \& Cie, 1923. v. 2.

GROTTI, Dinorá Adelaide Musetti. Teoria dos serviços públicos e sua transformação. In: SUNDFELD, Carlos Ari (Coord.). Direito administrativo econômico. São Paulo: Malheiros, 2002.

JUSTEN, Mônica Spezia. A noção do serviço público no direito europeu. São Paulo: Dialética, 2003.

LA TORRE, Michele. Nozione di diritto amministrativo. Roma: Stamperia Reale di Roma, 1935.

LANDI, Guido; POTENZA, Giuseppe. Manuale de diritto amministrativo. Milano: D. A. Giuffrè, 1963.

MALEZIEUX. Raymond. Manuel de droit administratif. Paris: Cujas, 1954.

MEIRELLES, Hely Lopes. Direito administrativo brasileiro. 25. ed. São Paulo: Malheiros, 2000.

MELlO, Celso Antônio Bandeira de. Curso de direito administrativo. São Paulo: Malheiros, 2006.

TRIBUNAL DE CONTAS DA UNIÃO. Auditoria de natureza operacional. Disponível em: <http://portal2.tcu.gov.br/portal/page/portal/TCU/ comunidades/programas_governo/historico >. Acesso em: 9 fev. 2010.

TRIBUNAL DE CONTAS DA UNIÃO. Acórdão 68/2003-TCU-Plenário. Disponível em: <http://contas.tcu.gov.br/portaltextual/MostraDocumento $? \mathrm{qn}=1 \& \mathrm{doc}=2 \& \mathrm{dpp}=20 \& \mathrm{p}=0>$. Acesso em: 17 fev. 2010 .

TRIBUNAL DE CONTAS DA UNIÃO. Acórdão 102/2007-TCU-Plenário. Disponível em: <http://contas.tcu.gov.br/portaltextual/MostraDocumento $? \mathrm{qn}=2 \& \mathrm{doc}=1 \& \mathrm{dpp}=20 \& \mathrm{p}=0>$. Acesso em: 17 fev. 2010 .

TRIBUNAL DE CONTAS DA UNIÃO. Acórdão 2.154/2007-TCU-Plenário. Disponível em: <http://contas.tcu.gov.br/portaltextual/MostraDocumento ? $\mathrm{qn}=3 \& \mathrm{doc}=2 \& \mathrm{dpp}=20 \& \mathrm{p}=0>$. Acesso em: $17 \mathrm{fev} .2010$. 
TRIBUNAL DE CONTAS DA UNIÃO. Acórdão 556/2004-TCU-Plenário. Disponível em: <http://contas.tcu.gov.br/portaltextual/MostraDocumento ? $\mathrm{qn}=4 \& \mathrm{doc}=2 \& \mathrm{dpp}=20 \& \mathrm{p}=0>$. Acesso em: $17 \mathrm{fev} .2010$.

TRIBUNAL DE CONTAS DA UNIÃO. Acórdão 1.756/2004-TCU-Plenário. Disponível em: <http://contas.tcu.gov.br/portaltextual/MostraDocumento ?doc $=5 \& \mathrm{p}=0 \& \mathrm{qn}=1 \&$ templ=default $>$. Acesso em: 24 nov. 2010.

VEDEL, M. Georges. Cours d'institutions administratives. Paris: Les Cours de Droit, 1961-1962.

ZYMLER, Benjamin; ALMEIDA, Guilherme Henrique de La Rocque. O controle externo das concessões de serviços públicos e das parcerias público-privadas. Belo Horizonte: Fórum, 2005.

ZYMLER, Benjamin. Direito administrativo e controle. Belo Horizonte: Fórum, 2005. 